\title{
Gunky time and indeterminate existence
}

\section{Giuseppe Spolaore}

\author{
Università degli Studi di Padova \\ Department of Philosophy, Sociology, Education and Applied Psychology \\ Padova, Veneto \\ Italy \\ giuseppe.spolaore@gmail.com
}

Article info

CDD: 115

Received: 15.03.2017; Accepted: 15.03.2017

DOI: http://dx.doi.org/10.1590/0100-6045.2017.V40N1.GS

\author{
Keywords \\ Event of coming to be \\ Instant \\ Time atom \\ Continuum \\ Indeterminate existence
}

\begin{abstract}
The paper criticizes an argument recently presented by Ross Cameron. The argument purports to show that, if time is gunky (that is, if there are no time atoms), and if changes in existence are underwritten by events of coming to be, then there are cases of indeterminate existence. The putative reason is that, if time is gunky, then events of coming to be cannot be instantaneous, and hence, changes in existence must be gradual, non-clear-cut. The paper argues that this argument conflates two different readings of "event of coming to be". Under one reading, the argument is unsound. Under the other, the argument is valid only if a further, nontrivial premise is added, which concerns the relation between time atoms, instants, and instantaneous events.
\end{abstract}

The aim of this paper is to criticize an argument presented in a recent book by Ross Cameron (2015). The aim might seem modest - the argument is put forth in a somewhat casual and tentative way in the book -, but the reasons why the argument fails have general interest.

Here are the premises of the argument:

(1) Time is gunky (viz., any temporal interval has proper parts);

(2) Changes in existence are underwritten by Aristotelian events of 'coming to be';

Manuscrito - Rev. Int. Fil. Campinas, v. 40, n. 1, pp. 81-86, jan.-mar. 2017. 
and here is the conclusion:

(C) There must be cases of indeterminate existence.

It is useful to break Cameron's reasoning into two parts. This is the first one: [Consider arbitrary object A and] suppose A exists, but didn't always exist. By (2) there must have been an event of A's coming to be. Given (1), this event was not instantaneous. No event is instantaneous, because there are no instants: there are only extended temporal regions, and hence every event occupies some extended temporal region. In that case, there can be no instantaneous transition from A's not existing to its existing: instead, there had to be an extended process during which A came to be. (184-185)

In a nutshell, if time is gunky, then there are no instants, and so:

(IC) No event of coming to be is instantaneous. Any thing comes into existence through an extended process.

The second part of the reasoning leads from intermediate conclusion (IC) to (C):

Now what should we say about the status of A during this event? Not that it exists $[\ldots]$ for then it would have already come to be. But not that it doesn't exist, either, [...] for there is a difference concerning A's being from before it started coming to be and now when it is coming to be. So we should say [...] that while $\mathrm{A}$ is coming to be, its ontological status is indeterminate: 'A exists' is neither determinately true (as it will be once it has come to be), but nor is it determinately false (as it was before it started to come to be) - it is indeterminate whether it is true or false. (185)

For our purposes, it is useful to focus on a key assumption Cameron makes in this part, namely:

(3) There is a difference in A's being from before and after the time at which the event of A's coming to be begins; that is, the beginning of the event of A's coming to be marks a difference in the ontological status of A.

Manuscrito - Rev. Int. Fil. Campinas, v. 40, n. 1, pp. 81-86, jan.-mar. 2017. 
So much for a general presentation of Cameron's argument. Now let us see what is wrong with it.

Consider an expression like "event of A's coming to be". As a matter of fact, we can use it in at least two different ways:

(I) we can use it to denote an accomplishment (see Vendler 1957), that is, a temporally extended activity with a culmination. The accomplishment of A's coming to be is an event that leads from a state at which A does not exist to a state at which A exists, generally by playing a distinctive causal role in the transition. Standard examples of accomplishments of coming to be are the building of a house and the assembling of a composite artefact from scattered parts. Actually, Aristotle's own examples in his Physics, I, are precisely of this kind;

(II) we can use it in a more abstract fashion, to indicate a transition from a state at which A does not exists to a state at which A exists. ${ }^{1}$ So understood, events of coming to be need not play any causal role at all.

Now, as we shall see, the impression that Cameron's argument is valid rests on equivocation. Depending on what reading of "the event of A's coming to be" is chosen, different steps in the reasoning become valid, but there is no single reading that validates the whole argument. More precisely, reading (I) makes the first part of Cameron's argument valid (albeit in a somewhat vacuous way) and the second invalid, and indeed very weak. As for reading (II), the situation is precisely reversed: the second part of the argument is (somewhat vacuously) valid and the first invalid, and philosophically unconvincing. Let us consider cases (I) and (II) in turn.

(I) Let us assume that an event of A's coming to be is an accomplishment that culminates in A's existence. If so, intermediate conclusion (IC) is obviously true, for all accomplishments are temporally extended. However, as we have seen, the step from (IC) to (C) crucially involves assumption (3),

1 Transitions of coming to be, so understood, are close to what Vendler (1957) calls achievements, that is, events that have a culmination but, unlike accomplishments, have no inner telic complexity (standard examples: reaching the summit, winning the game, dying). However, I prefer not to use the word "achievements" here, for achievements are generally thought to be instantaneous events, and to insist on this feature would beg the question against Cameron's intermediate conclusion (IC).

Manuscrito - Rev. Int. Fil. Campinas, v. 40, n. 1, pp. 81-86, jan.-mar. 2017. 
that is, the view that an event of A's coming to be marks "a difference concerning A's being" from its very beginning. Unfortunately, this assumption need not be true under reading (I). Consider, for instance, a standard accomplishment of coming to be like the building of a house. It appears that, when the building begins, the house is firmly out of existence, exactly as it was before. Of course, one might insist that "exist" is vague, and that, at some point during the construction, the house is neither (determinately) in existence nor out of it. However, this view - right or wrong as it may be - makes the premise that time is gunky irrelevant to the argument. If "exist" is vague, we can reach conclusion (C) anyway, regardless of whether time is gunky. And if "exist" is not vague, and so there is no intermediate state between existence and nonexistence, the natural conclusion is that A begins to exist right at the end of the event of A's coming to be, and that it never existed before. Maybe Cameron's argument aims at showing that if time is gunky then "exists" must be vague, so that there can be no neat transition between existence and nonexistence? This leads us to the second understanding of "event of A's coming to be".

(II) If "event of A's coming to be" is taken to denote a transition between a state at which A exists (let us call it " $A$ exists") to a state at which A does not exist (" $A$ does not exist"), then (IC) boils down to:

(IC2) The transition from $A$ does not exist to $A$ exists cannot be neat.

However, (IC2) does not follow from (1)-(3). To see why, suppose that the timeline is gunky and there exist intervals of time Black and White such that:

- Black completely precedes White (Black < White in symbols), and

- Black and White are adjacent (no interval $\mathrm{T}$ is such that Black $<\mathrm{T}<$ White).

Now assume that object A never exists during Black and always exists during White (see Figure 1). If so, the transition from $A$ exists to $A$ does not exist is neat, and in no sense "an extended process".

Manuscrito - Rev. Int. Fil. Campinas, v. 40, n. 1, pp. 81-86, jan.-mar. 2017. 


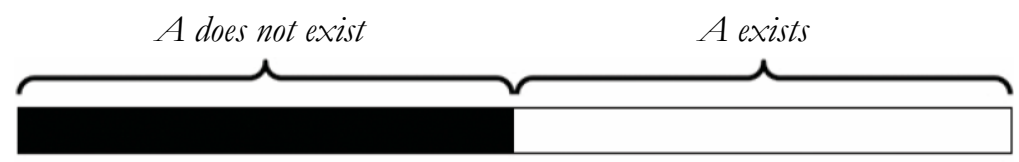

Figure 1.

If Cameron's argument is sound, the assumption that A never exists on Black and always exists on White is inconsistent with (1), for (1) entails that no such neat transition can take place. However this is false: there exists a consistent, atomless mereological theory that allows for adjacent intervals (see Hellmann and Shapiro 2013; it is worth noting that this work is explicitly based on Aristotle's atomless conception of the continuum - see also Hellmann and Shapiro 2015 for a historical survey of the atomless conception).

Plausibly, under reading (II), the argument from (1)-(2) to (IC) is not only deductively invalid but also philosophically unconvincing, in the sense that, if one subscribes to (1)-(2), then one is very likely to reject (IC). After all, those philosophers who deny the existence of atomic temporal parts are generally driven, like Aristotle, by the will to avoid Eleatic qualms about 'the instant of change'. On the face of it, it is unlikely that they subscribe to (IC), that is, that they are prepared to replace the non-existent instant of change (understood as a time atom) with a full interval of change. In their eyes, this move would only reinstall Zeno's conclusion that between any two incompatible states in time must lie some 'middle men', which postpone change and eventually make it impossible.

An atomless conception of time does not entail that instants do not exists, but only that they are not atomic parts of the timeline. (For instance, following Hellman and Shapiro's (2013) treatment of points, we might identify instants with Cauchy sequences of intervals, but there are many alternative possibilities - see again Hellmann and Shapiro 2015 for a survey.) Thus, there is no inconsistency in claiming that there exists an instant - 'the instant of change' - that lies between Black and White, and denying that there are time atoms. Correspondingly, there is no inconsistency in admitting that there are instantaneous events and denying that any event exists, which only occupies a time atom. There is a telling analogy here between events (qua transitions) and borders. When we say that the border between, e.g., a black and a white area is neat, we need not (and generally do not) mean that the

Manuscrito - Rev. Int. Fil. Campinas, v. 40, n. 1, pp. 81-86, jan.-mar. 2017. 
border occupies a region of space that is one space atom wide. And this is especially so if we think that space atoms do not even exist! Within an atomless conception of space, it is natural to think of neat borders as entities that supervene on certain spatial features of extended areas, not to deny their existence. Analogously, instantaneous events need not be conceived as events that fully occupy an atomic part of the timeline.

To summarize, "event of A's coming to be" can receive two readings, which I have indicated as (I) and (II).

Under reading (I), an event of A's coming to be is an extended activity that culminates in the existence of A. However, an event of A's coming to be, so conceived, need not mark a difference in the ontological status of A from its very beginning, against premise (3).

Under reading (II), an event of A's coming to be is a transition between a state at which A does not exist and a state at which A exists. Under this reading, Cameron's argument is valid only if some further premise is assumed to be true. As a matter of fact, Cameron presupposes a specific conception of instants, according to which they are atomic temporal parts of the timeline (and, as a consequence, instantaneous events are events that fully occupy atomic temporal parts of the timeline). For all that has been said so far, this conception may very well be true. However, as I have argued, it is not forced upon us. Moreover, it is unlikely that one finds it very appealing if one believes, in accordance with premise (2), that atomic temporal parts do not even exist.

\section{References}

CAmeron, R. The Moving Spotlight. Oxford: Oxford University Press, 2015.

Hellman, G. and Shapiro, S. The classical continuum without points. Review of Symbolic Logic, 6 (3): 488-512, 2013.

Hellman, G. and Shapiro, S. Frege meets Aristotle: Points as abstracts. Philosophia Mathematica, 25 (1): 73-90, 2015.

VendLer, Z. Verbs and times. Philosophical Review, 66 (2): 143-160, 1957.

Manuscrito - Rev. Int. Fil. Campinas, v. 40, n. 1, pp. 81-86, jan.-mar. 2017. 